\title{
O uso dos emojis na construção de sentidos do discurso multimodal
}

\author{
Albertina Maria de Melo Tenório ${ }^{1}$
}

\section{Resumo}

Esta narrativa tem o objetivo de abordar sobre a contribuição do Letramento Digital no desenvolvimento das produções textuais multimodais online, dos graduandos em Letras. Fundamentamo-nos na perspectiva interacionista, discursiva e dialógica, que considera o discurso como produto social e a prática discursiva em semiosfera digital, como produto do desenvolvimento advinda de outros letramentos, inserido-se no Macroletramento, compreendido como capacidade de uso de vários letramentos no meio digital. Ancorados nesta forma de abordagem, foi realizada uma atividade prática em sala de aula, tendo por ambiente de aprendizagem a plataforma digital WhatsApp (aplicativo de mensagens instantâneas). Na atividade proposta, os graduandos foram orientados a fazer uso exclusivo dos emojis (elementos imagéticos). 0 estudo aqui apresentado baseia-se epistemologicamente nas investigações de Dudeney, Hockly e Pegrum (2016) sobre Letramentos Digitais e suas variedades; Ribeiro (2016) e sua definição de texto multimodal pautada na ideia de "poder semiótico"; Kress e Van Leeuwen (2006) sobre o incremento das novas linguagens aos textos verbais; Coscarelli (2016) a respeito da multimodalidade como combinações entre duas ou mais modalidades da linguagem; e Bourdieu (2004) com o conceito de Habitus. Por fim, os resultados apontaram para o fato de que o uso, em sala de aula, de discursos multimodais/multissemióticos, trabalhados por meio dos Letramentos Digitais, é essencial para o desenvolvimento de habilidades necessárias, na atuação do sujeito em esfera digital, bem como em sua ação comunicativa competente, interativa, dialógica e participativa diante do universo tecnológico que o circunda.

Palavras-chave: Letramento digital. Emoji. Discurso multimodal. Multissemiótico.

\section{Introdução}

Muito se fala sobre o letramento digital nos estudos atuais da linguagem. Diante dessa floresta tecnológica digital em que vivemos, nossas ações comunicativas estão cada vez mais visíveis e plausíveis de estudo e investigação.

O interessante é que, por mais que este tema seja discutido na comunidade acadêmica, especificamente nos cursos de pós-graduação strictu sensu, ainda é muito incipiente nos cursos de graduação em Letras, de forma geral.

Nas salas de aula da Educação Básica, a temática, pelo menos na grande maioria das escolas, basicamente inexiste, apesar de os estudantes estarem ambientados no universo digital 24 horas, produzindo textos multimodais/multissemióticos, curtindo textos,

\footnotetext{
${ }^{1}$ Doutoranda do curso de Ciências da Linguagem pela Universidade Católica de Pernambuco (albertinamelo@hotmail.com)
} 
comentando e, principalmente, compartilhando seus discursos e os discursos do outro, numa atividade incessante, interativa e participativa de atuação discursiva online.

Por isso, nesta pesquisa, trazemos uma experiência prática de atividade realizada com graduandos do $2^{\circ}$ período do curso de Letras, para demonstrar a possibilidade de desenvolvimento do Letramento Digital, considerado aqui como Macroletramento, uma vez que envolve o trabalho simultâneo de vários letramentos.

\section{0 letramento digital como base para a ação dialógica na esfera virtual}

Acredita-se que, na história da humanidade, o momento em que vivemos está sendo um dos mais marcantes no que diz respeito ao uso da tecnologia e seus avanços. Estamos imersos em esferas tecnológicas durante as 24 horas de nosso dia a dia. Estamos conectados e ambicionamos ampliar essas conexões em níveis de progressões geométricas.

A virtualidade, e sua capacidade de imitar nossos processos mentais de interconexões, tornou-se o habitus em seu sentido mais bourdieriano de concepção. Uma vez que ela apresenta o conjunto de elementos necessários à nossa atuação enquanto sujeitos discursivos do locus digital.

Ampliando essa percepção, e associando-a à perspectiva sociológica de Bourdieu (2004), de que a construção do habitus está intimamente atrelada ao conjunto de interações que realizamos na vida, podemos afirmar que esse habitus seriam:

Esquemas de percepção e de ação que o agente social incorpora ao longo de suas trajetórias sociais, em geral, trajetória familiar, educacional, religiosa, profissional, econômica, e que se encontram presentes em sua subjetividade (para não dizer em sua mente ou consciência) de modo duradouro e que, de certa maneira, orientam o sentido de suas ações (SILVA, 2013, p. 160).

Nesse sentido, acreditamos que a esfera da virtualidade tornou-se esse espaço em que as ações dos sujeitos do discurso, ações estas que sempre aconteceram ao longo da história e na sociedade, tornam-se visíveis, e mais, esses elementos que estão presentes em sua subjetividade e que se manifestam nos enunciados concretos que os sujeitos realizam em sua prática diária de comunicação, ficaram passíveis de observação e estudo, como o que iremos depreender aqui neste texto. 
Seguindo esse viés, também percebemos que o processo dialógico presente nessa esfera requer dos sujeitos certas habilidades e competências de comunicação para atuar no mundo tecnológico digital. É aqui que partimos da ideia de letramentos, ou seja, para determinadas áreas do saber, há uma variedade de letramentos que serão a base de uma comunicação eficiente.

Vale ressaltar que, quando falamos em letramento, utilizamos esse termo em seu aspecto plural por defendermos a ideia de que ele vai muito além de um conjunto de práticas atreladas ao processo de leitura e escrita. Ele envolve o contexto social, a história, a cultura, o uso da tecnologia, habilidades de percepção de semioses como texturas, cores, tons, fontes, compreensão de gestos, de códigos e de toda uma gama de elementos que fazem parte da ação e atuação do sujeito no mundo, por isso o uso do termo letramentos, uma vez que agimos de formas múltiplas com e na sociedade.

Dentro dessa perspectiva, tomamos como parâmetro o conceito de Dudeney, Hockly e Pegrum (2016) ao afirmarem que:

Língua e letramento estão fortemente aglutinados um no outro: por uma parte, porque a verdadeira noção de letramento se baseia na língua; por outra, porque todos os letramentos se conectam com a comunicação de sentidos, seja por meio da linguagem, seja por outros canais frequentemente complementares (2016, p. 18).

Os autores ainda citam Barton (1994), Barton e Hamilton (2000) e Rheingold (2012) para reforçarem a importância dos letramentos não apenas como habilidades ou competências, mas como práticas sociais engajadas na ação comunicativa humana.

No entanto, mesmo diante dessa pluralidade de letramentos ou letramentos múltiplos, sabemos que há uma forma de letramento basilar para o desenvolvimento dos demais, estamos falando do letramento impresso.

O letramento impresso refere-se à:

Habilidade de compreender e criar uma variedade de textos escritos que abrange 0 conhecimento de gramática, vocabulário e características do discurso simultaneamente com as competências da leitura e da escrita (DUDENEY; HOCKLY, PEGRUM, 2016, p. 23). 


\section{LínguaTec}

Podemos afirmar, então, que antes de sua atuação em esfera tecnológica digital é necessário que o sujeito do discurso seja alguém com certo nível de letramento impresso. É possível, ainda, afirmar que ele saiba fazer uso do inventário linguístico, que consiga utilizar com certa desenvoltura os recursos da língua e seus mecanismo de materialização discursiva. Mesmo porque esse sujeito da esteia tecnológica digital não quer apenas ser lido, ele almeja ser curtido, comentado, compartilhado e, assim, ampliar suas conexões e atuações em rede.

No entanto, como afirmamos anteriormente, o letramento impresso é apenas um dos letramentos-chave que corroboram para o desenvolvimento do que se pode chamar de macroletramento, ou seja, são letramentos que envolvem a ação simultânea de habilidades linguísticas, multimidiáticas, espaciais, cinestésicas e outras que pertencem a letramentos distintos (DUDENEY; HOCKLY, PEGRUM, 2016).

Dessa forma, podemos afirmar que os Letramentos Digitais que envolvem outros letramentos, a exemplo de: letramento impresso, letramento em SMS, letramento em hipertexto, letramento em multimídia, letramento em jogos, letramento móvel, letramento em codificação, sendo que todas essas formas de letramentos associadas à ação da linguagem formam o Macroletramento (DUDENEY; HOCKLY, PEGRUM, 2016), como se pode verificar no quadro a seguir.

\begin{tabular}{|c|c|c|}
\hline \multicolumn{3}{|c|}{ Quadro dos Letramentos digitais - Foco na linguagem } \\
\hline Nível de complexidade & Letramentos & Conceito \\
\hline \multirow[t]{2}{*}{ (:) } & Impresso & $\begin{array}{l}\text { Habilidade em criar textos } \\
\text { escritos a partir do uso de } \\
\text { elementos da gramática, do } \\
\text { vocabulário e de características } \\
\text { do discurso atrelados às } \\
\text { capacidades de leitura e } \\
\text { escrita. }\end{array}$ \\
\hline & SMS & $\begin{array}{l}\text { Habilidade de se comunicar } \\
\text { eficientemente em internetês } \\
\text { (uso de abreviações, } \\
\text { emoticons/emojis) }\end{array}$ \\
\hline (i) (-) & Hipertexto & $\begin{array}{l}\text { Habilidade de processar } \\
\text { hiperlinks apropriadamente e } \\
\text { de usá-los para incrementar } \\
\text { com eficiência um documento } \\
\text { ou artefato. }\end{array}$ \\
\hline (;) (-); & Multimídia & Habilidade de interpretar e de \\
\hline
\end{tabular}




\begin{tabular}{|c|c|c|}
\hline & & $\begin{array}{l}\text { criar efetivamente textos em } \\
\text { múltiplas mídias, } \\
\text { especialmente usando imagens, } \\
\text { sons e vídeo. }\end{array}$ \\
\hline \multirow[b]{2}{*}{ (;) ; ; ; } & Jogos & $\begin{array}{l}\text { Habilidade de navegar e } \\
\text { interagir eficientemente nos } \\
\text { ambientes de jogos e de } \\
\text { alcançar objetivos no interior } \\
\text { deles. }\end{array}$ \\
\hline & Móvel & $\begin{array}{l}\text { Habilidade de navegar, } \\
\text { interpretar informação, } \\
\text { contribuir com informação e se } \\
\text { comunicar por meio da internet } \\
\text { móvel, incluindo a habilidade } \\
\text { de se orientar no espaço da } \\
\text { internet das coisas (onde a } \\
\text { informação dos objetos do } \\
\text { mundo real está integrada à } \\
\text { rede) e da realidade aumentada } \\
\text { (onde a informação proveniente } \\
\text { da internet se sobrepõe ao } \\
\text { mundo real). }\end{array}$ \\
\hline (;) $;(;)+(;)$ & Codificação & $\begin{array}{l}\text { Habilidade de ler, escrever, } \\
\text { criticar e modificar códigos de } \\
\text { computador em vista de criar } \\
\text { ou confeccionar softwares e } \\
\text { canais de mídia. }\end{array}$ \\
\hline
\end{tabular}

Quadro 1: Letramentos digitais

Fonte: adaptado de DUDENEY; HOCKLY, PEGRUM, 2016, p. 21

Como se pode notar, diante das habilidades que pretendem ser desenvolvidas em cada letramento, todas convergem para uma percepção mais ampla do Letramento Digital como um Macroletramento, pois instigam a desenvoltura de habilidades, individuais e sociais, com o objetivo de fazer com que o sujeito discursivo digital possa "interpretar, administrar, compartilhar e criar sentido eficazmente no âmbito crescente dos canais de comunicação digital" (DUDENEY, HOCKLY, PEGRUM, 2016, p. 17).

\section{Letramento em SMS e o Letramento multimídia como elementos relevantes na construção do discurso multimodal}

O que gostamos de fazer quando não temos nada para fazer? Em geral, estamos conectados, seja no Facebook, no WhatsApp, no Instagram, enfim, nas variadas redes 
sociais em que interagimos no nosso dia a dia. Normalmente, na utilização dessas esferas, uma das regras intuitivas é a de economia linguística. Queremos ser entendidos com poucas palavras, por isso fazemos usos de abreviações e de imagens icônicas, a exemplo dos emojis.

Isso acontece porque nosso cérebro é alimentado por padrões, sabemos que nesses espaços um dos padrões é reduzir o uso vocabular, porque o fluxo da informação, a velocidade do discurso, nos impede de seguir à risca a escrita adequada das palavras, bem como a formalidade dos discursos, a não ser que esta norma seja convencionalizada anteriormente entre os usuários, como por exemplo, em um debate regrado via rede social.

Podemos deduzir, então, que atuar no universo virtual requer domínio e competência no uso da linguagem em esfera digital. Nesse sentido, a constituição da linguagem, nesse território, aponta para outras regras, a exemplo de conteúdo discursivo próprios para a semiosfera digital, ou, como afirmam Dudeney, Hockly e Pegrum (2016), sobre o uso dessa linguagem ou internetês, de que é uma "longa tradição de brincar com a língua” que surgiu com o uso de mensagens de texto via celular.

\footnotetext{
Esse tipo de linguagem surgida nas salas de bate-papo online e em mensagens de texto via celular, com algumas de suas abreviações servindo para a rapidez $e$ contenção de custos e, outras vezes, junto com emoticons, ajudando a evitar malentendidos nesses canais desprovidos de grandes recursos, dedicados exclusivamente à comunicação por texto (DUDENEY; HOCKLY; PEGRUM, 2016, p. 24).
}

Podemos observar que, com as novas plataformas de mídias sociais, é possível atrelarmos concomitantemente textos, imagens, vídeos, arquivo de áudio, emojis, dentre outros elementos semióticos utilizados para dar sentido ao processo enunciativo.

A essa forma de domínio e habilidade de ação discursiva, com o uso do internetês, chamamos de Letramento em SMS. Essa modalidade de letramento aproxima-se de nossa produção enunciativa de gírias, podendo ser uma base para mostrar aos sujeitos do discurso, o quando, o onde e como usar uma variação da língua em ambiente digital (DUDENEY; HOCKLY; PEGRUM, 2016).

Vale a pena salientar, como bem afirmam Dudeney, Hockly e Pegrum (2016, p. 25), que o uso da linguagem da internet "é um componente-chave de uma tendência digital 


\section{LínguaTec}

mais ampla voltada para uma crescente efemeridade, fragmentariedade, quantidade e rapidez da escrita".

Atualmente, só no Brasil, somos mais de 105 milhões $^{2}$ de usuários do mundo digital, em sua maioria leitores/autores em telas touchscreen, por isso essa necessidade iminente de rapidez, pois nossos objetos de interação deixaram de ter apenas vida impressa para se tornarem objetos ricos de informação online. Em geral, tais objetos são signos repletos de conceitos ideológicos, formados pela junção de outros signos, ou seja, nossos objetos discursivos são construções multissemióticas/ multimodais.

Isso se dá porque “em vez de figurar sozinho, frequentemente, o texto é um complemento, ou complementado por outras formas de comunicar sentido", como defende Dionísio (2016, p. 29). Desde fontes, cores, luz, posicionamento de objetos, espaçamentos de parágrafos, etc. Todos esses elementos no plano da materialidade até o uso paralelo de vídeos, áudios, emoticons em uma mesma produção discursiva, são aspectos multimodais de construção e efeito de sentidos.

O novo leitor/autor precisa administrar as habilidades de interpretar e, ao mesmo tempo, produzir textos que deem conta de suas necessidades reais de comunicação, interação e participação. Ele precisa não apenas, “entender, mas criar mensagens multimídia, que integrem textos com imagens, sons e vídeos que se ajustem a uma variedade de propósitos comunicativos e alcancem uma gama de público-alvo" (DUDENEY; HOCKLY; PEGRUM, 2016, p. 29).

Isso porque, mais do que navegar, esse novo sujeito do discurso online, precisa “desenvolver a capacidade de identificar as necessidades de dizer e alinhá-las ao manejo de certas linguagens" (RIBEIRO, 2016, p. 103), ou seja, ele precisa ter o "poder semiótico”, para tornar seu discurso responsivo em ambiente digital.

Esse poder está atrelado ao como dizer e de que forma dizer, fazendo uso dos diversos signos que estão à sua disposição. A sua competência nessa esfera está atrelada não ao seu talento, em outras palavras, o sujeito não precisa ser um designer, mas precisa

\footnotetext{
${ }^{2}$ Dados disponíveis no http://tobeguarany.com/internet-no-brasil/. Acesso em: 21.11.2016. As informações são referentes ao ano de 2013.
} 
saber utilizar as diversas linguagens de que dispõe para produzir possíveis efeitos de sentidos em seus interlocutores.

Concordamos com Ribeiro (2016, p. 115) quando afirma que:

um texto multimodal não é apenas aquele em que duas ou mais linguagens convivem, em algum tipo de relação, como complementaridade, redundância, discordância, etc. Um texto multimodal é uma peça que resulta de escolhas de modulações, inclusive dentro da mesma semiose.

Nesse sentido, podemos afirmar que a questão do poder semiótico, como abordada anteriormente, está mais atrelada a uma seleção, a uma escolha do sujeito do discurso que ao formular seus enunciados concretos utiliza-se dos elementos signícos que conhece e que permeiam seu mundo real. Embora, haja situações em que os objetos do mundo real sirvam para criar, relacionar, apresentar ou presentificar um mundo fictício, como no caso das imagens digitais.

O "poder semiótico" (KRESS, 2003) das pessoas se amplia, portanto, quando elas sabem que têm variados recursos para expressar algo. Seja com palavras ou imagens, som ou gesto; seja com cores ou vocabulário, elas precisam ganhar intimidade com as linguagens disponíveis, com e sem computadores e editores de texto e imagem (RIBEIRO, 2016, p. 115).

Mais adiante, veremos como essas escolhas multissemióticas ou multimodais são usadas para a produção de sentidos e de forma elas contribuem para a progressão enunciativa e a compreensão discursiva.

\section{Os emojis ${ }^{3}$ e a construção de sentidos no discurso}

Como foi visto no tópico anterior, o mundo digital requer uma própria linguagem, uma linguagem que dê conta das variadas formas que temos para entrar em interação com o mundo à nossa volta. Dessa forma, um dos elementos mais recorrentes, principalmente nas redes sociais, é o Emoji.

\footnotetext{
${ }^{3}$ Também considerados como ideogramas, que expressam uma palavra ou enunciado completo como possibilidade de recurso para suas construções enunciativas.
} 


\section{LínguaTec}

Emoji é uma palavra de origem japonesa, constituída pela junção de $\boldsymbol{e}$ (imagem) e moji (letra). Nesse sentido, Emoji é um pictograma, ideograma, que tem por função transmitir o sentido de uma ideia completa, de uma palavra, uma expressão, um sentimento ${ }^{4}$.

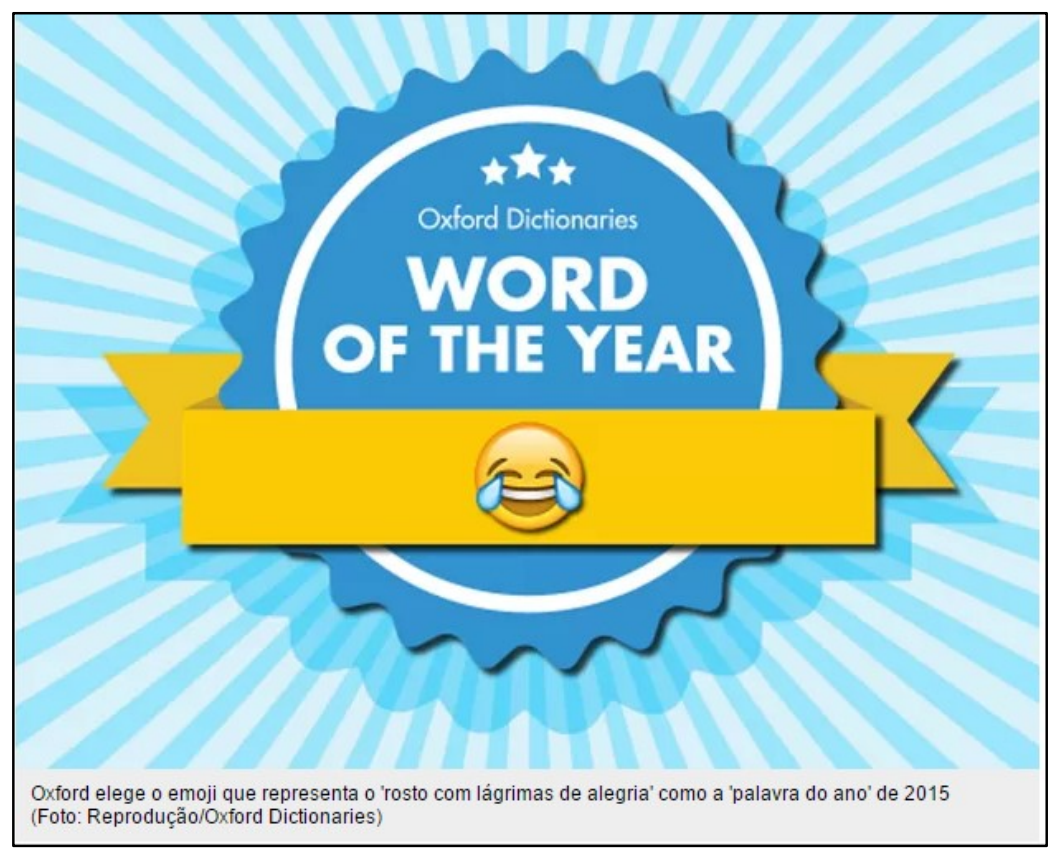

Figura 1: Selo de palavra do ano de 2015

Fonte: http://gl.globo.com/educacao/noticia/2015/11/emoji-e-eleito-pela-1-vez-palavra-do-ano-pelodicionario-oxford.html

Os primeiros emojis surgiram na década de 1990, no Japão, e foram criados por Shigetaka Kurita, membro da NTT DoCoMo - principal empresa de telefonia móvel do Japão. Diferente dos emoticons, embora haja certa similitude com estes, os emojis são predominantemente imagéticos, enquanto os emoticons são caracteres gráficos que se aglutinam para expressar um sentimento, uma emoção, a exemplo de:

${ }^{4}$ Dados coletados na página https://www.significados.com.br/emoji/. Acesso em: 21.11.2016. 


\begin{tabular}{|c|c|c|c|c|c|c|}
\hline (:) & (:) & (:) & (:) & (:) & ;); & (:) \\
\hline :) & : & $: p$ & $=\mathrm{D}$ & :o & ;) & $: \mathrm{v}$ \\
\hline (2): & (:) & ; (2) & (2) & 이 & $\theta$ & 0 \\
\hline$>:($ & / & :'( & $\hat{\wedge}$ & 8) & $\mathrm{B} \mid$ & $<3$ \\
\hline (-); & (:) & $\Theta$ & (:) & $\Theta$ & (2): & [3 \\
\hline 3:) & O:) & $\because$ & 0.0 & $>: 0$ & :3 & (y) \\
\hline
\end{tabular}

Figura 2: Emoticons

Fonte: http://www.techtudo.com.br/noticias/noticia/2013/10/coracao-joinha-saiba-usar-no-facebookemoticons-tradicionais.html

Foi por meio da percepção de seu potencial cultural e criativo, que escolhemos os emojis para análise da produção discursiva, realizada em um grupo de graduandos em Letras. Como se sabe, o WhatsApp é um aplicativo multiplataforma de mensagens instantâneas compatível com grande parte dos sistemas operacionais (Android, IOs, Windows Phone, BlackBerry OS 10.0.10.82 (10.0.10.648.) ou superior etc).

A função primordial do WhatsApp é iminentemente dialógica, ou seja, os usuários trocam além de mensagens de texto e de voz, imagens, vídeos, arquivos em pdf, e ainda podem realizar chamadas sem custo, sendo necessárias apenas uma boa conexão via wi-fi, 3G ou 4G.

Os discursos que serão analisados se referem a uma proposta de atividade realizada por graduandosdo II período de Letras, da Faculdade de Formação de Professores da Mata Sul, (FAMASUL), que estudam a disciplina de Prática Pedagógica II. Ressaltamos que os graduandos são principiantes, ainda não tiveram contato com as principais vertentes teóricas dos estudos da linguagem e desconhecem a ideia de Letramento Digital.

A proposta de atividade foi a seguinte: Cada participante do grupo vai colocar (só usando emojis) o nome ou estrofe de uma música para os demais adivinharem, a 


\section{LínguaTec}

propositura serviu de "gancho" para toda a construção discursiva, como se pode observar nas figuras a seguir.

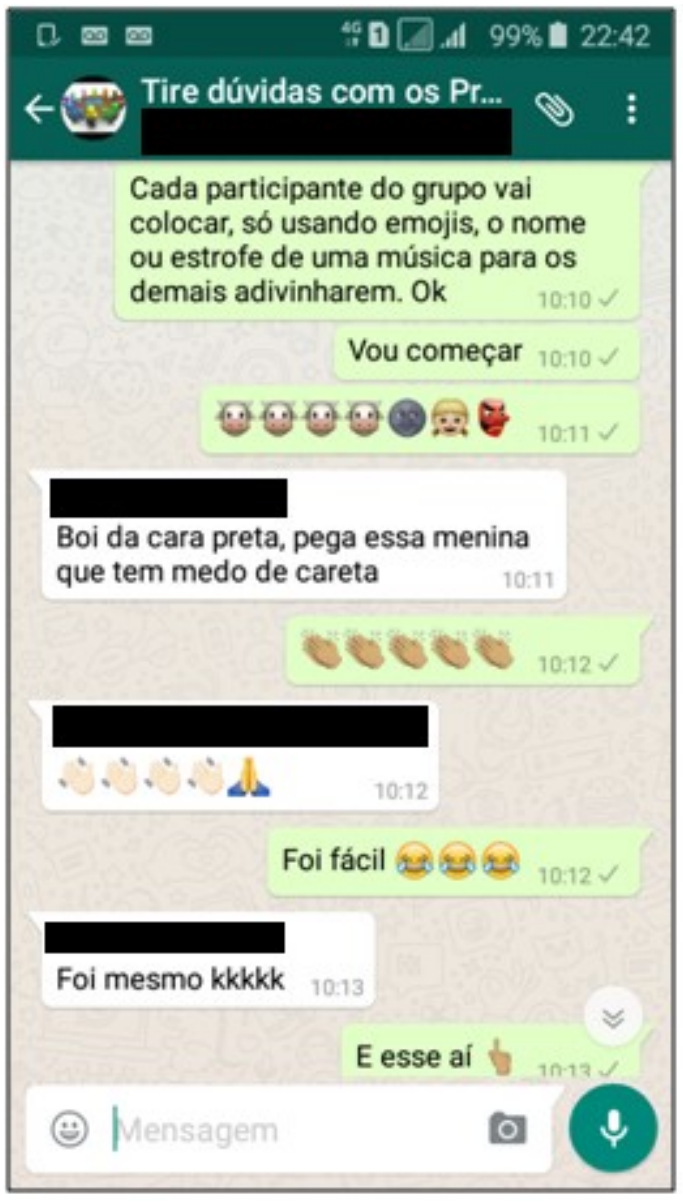

Figura 3: Atividade realizada na rede social WhatsApp

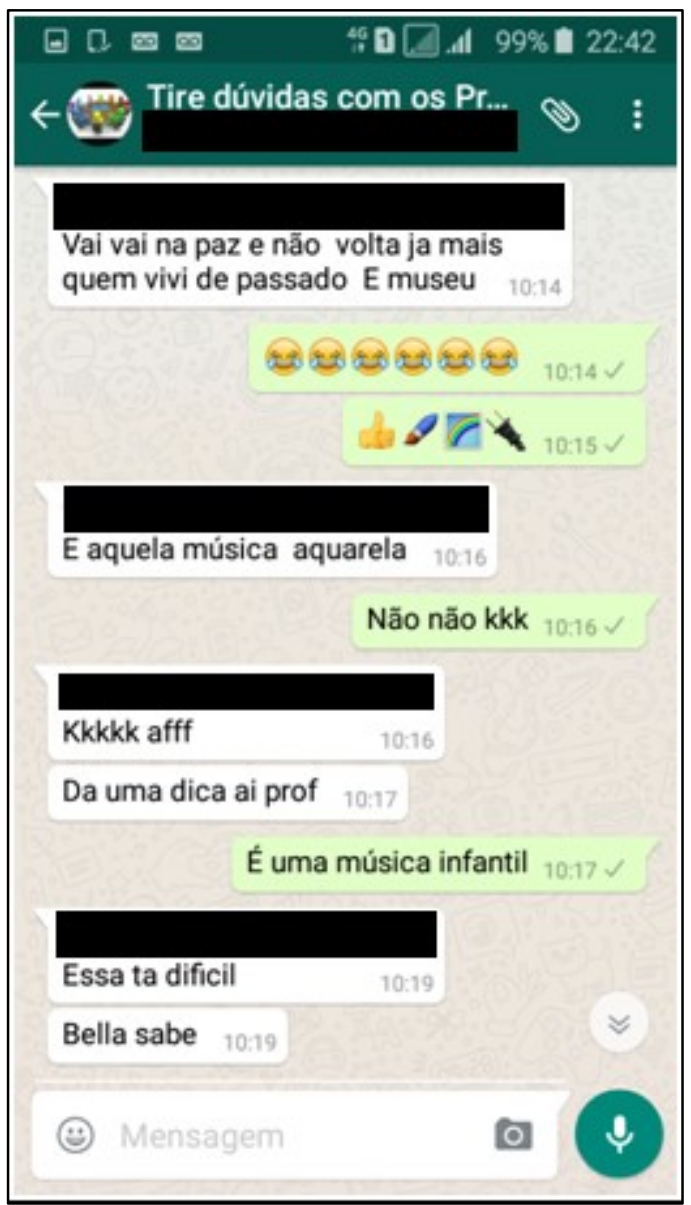

Figura 4: Atividade realizada na rede social WhatsApp 


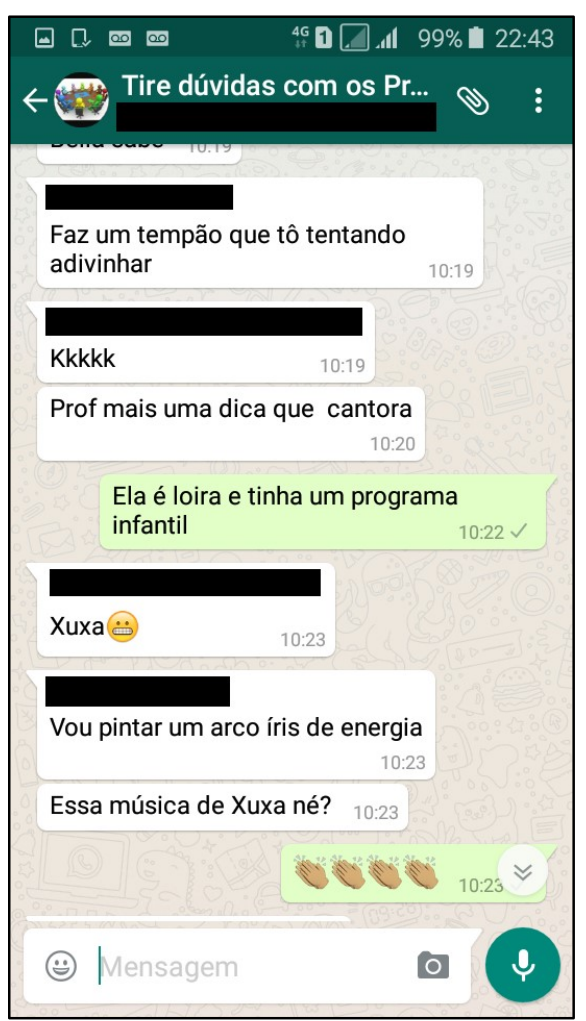

Figura 5: Atividade realizada na rede social WhatsApp

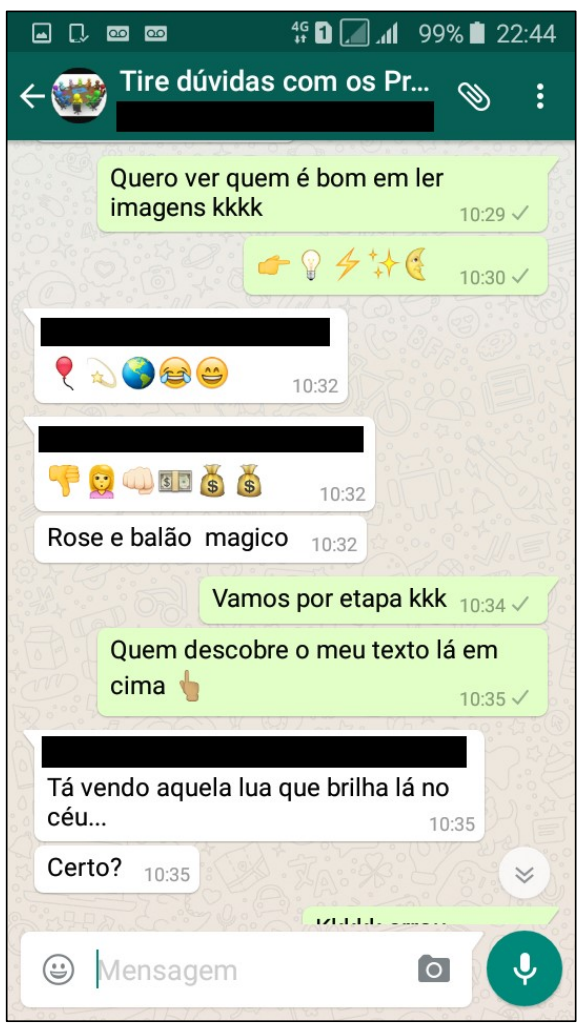

Figura 7: Atividade realizada na rede social WhatsApp

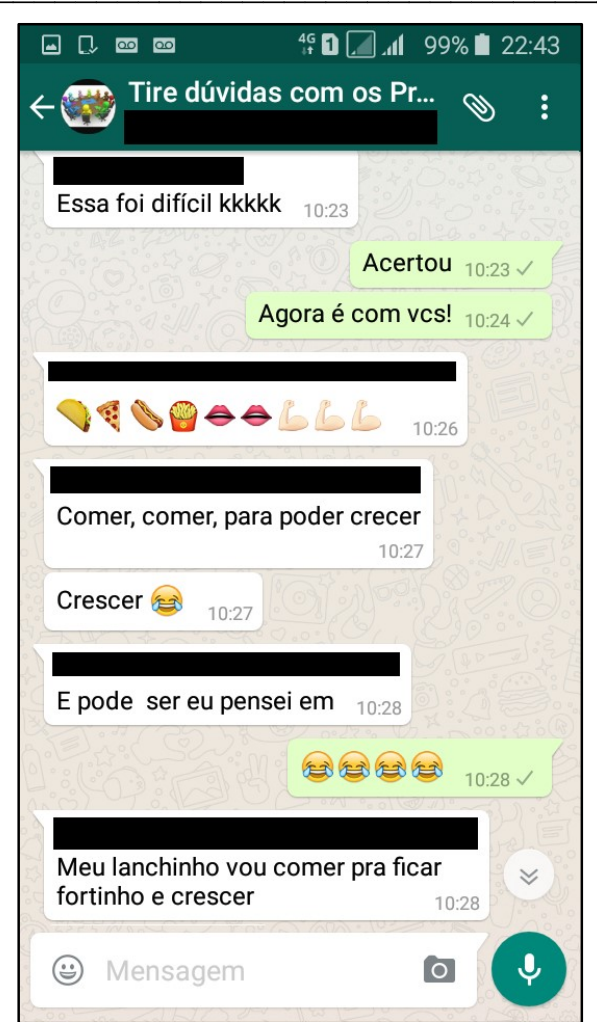

Figura 6: Atividade realizada na rede social WhatsApp

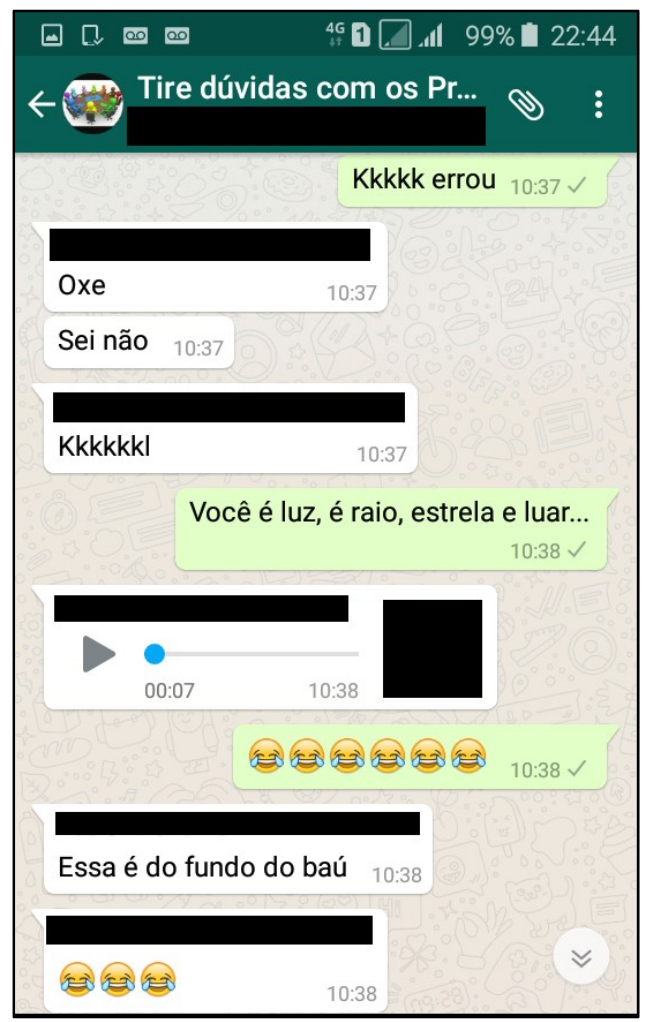

Figura 8: Atividade realizada na rede social WhatsApp 
Sabemos o quanto a tecnologia digital mudou nossa forma de interagir com o mundo à nossa volta, seja por meio da leitura ou da escrita. Não somos mais os mesmos leitores clássicos dos livros, das obras literárias, conhecido como leitor contemplativo. Atualmente, atuamos como sujeitos leitores/autores imersivos, responsivos, a tela, seja do computador ou do Smartphone, tornou-se nossa "porta de entrada" para esse processo de imersão e de responsividade. Vejamos os exemplos das figuras anteriormente apresentadas.

A teia de enunciados concretos foi iniciada por meio da proposta de atividade sugerida, atividade esta que também direciona as condições de produção do discurso (os enunciados só poderiam ser realizados via emojis), como se nota na figura 3.

A primeira sequência de emojis, que foi apresentada como exemplo (figura 3), além de servir como forma de brincar com a língua, a linguagem e a possibilidade de construção de sentidos do discurso, tornou-se um elemento-base para o desenvolvimento do macroletramento digital, em sua modalidade de aprendizagem via SMS e multimídia, fato que contribui para a consciência de uma comunicação específica em meio digital.

Essa possibilidade converge para o que Coscarelli (2016, p. 28) sinaliza ao afirmar que “as várias mídias já fazem parte da vida dos alunos, seja para divertir, compartilhar informações, interagir, fazer pesquisas ou jogar". Nesse sentido, ao lançar a proposta de atividade, não houve qualquer forma de rejeição, uma vez que os alunos já estão habituados a construir discursos multimodais em plataformas digitais, sendo, principalmente o uso dos emojis, uma prática comum no dia a dia de suas interações discursivas.

Notamos nas figuras 4, 5 e 6, que houve certos equívocos de interpretação da sequência de algumas imagens. Sabemos que os emojis, desde sua criação, são considerados como ideogramas e, nesse sentido, vistos como ícones. Os ícones funcionam como representantes de um conhecimento partilhado, são elementos que mantêm semelhança, analogias, com objetos do mundo, por isso o equívoco na interpretação da sequência imagética, uma vez que cada sujeito fez sua própria leitura de acordo com 0 conhecimento social, histórico, cultural que lhe é imanente.

Também vale a pena ressaltar como a sequência de emojis representa a estrutura do discurso verbal. Há um encadeamento de ideias, de informações, de ícones que reproduzem uma sintaxe enunciativa. Cada emoji ocupando o seu lugar no discurso, representando pela 


\section{LínguaTec}

imagem o que está expresso no discurso verbal, seja ele oral ou escrito. Como se pode notar no quadro 02:

\begin{tabular}{|c|c|}
\hline SEQ̨UÊNCIA DE EMOJIS & PRODUÇÃO DE SENTIDOS \\
\hline 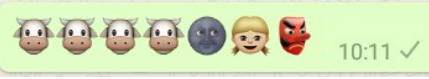 & $\begin{array}{c}\text { "Boi, boi, boi, boi da cara preta, pega essa menina que tem medo } \\
\text { de careta..." }\end{array}$ \\
\hline della & "Vou pintar um arco-íris de energia..." \\
\hline $08 \square 0 \Leftrightarrow B b B \quad 10.26$ & "Meu lanchinho vou comer pra ficar fortinho e crescer..." \\
\hline のターt & “Você é luz, é raio, estrela e luar...” \\
\hline Q 0 & $\begin{array}{c}\text { "Super fantástico, no balão mágico, o mundo fica bem mais } \\
\text { divertido..." }\end{array}$ \\
\hline Q & $\begin{array}{c}\text { “Não sei se dou na cara dela ou bato em você } \\
\text { Mas eu não vim atrapalhar sua noite de prazer } \\
\text { E pra ajudar a pagar a dama que lhe satisfaz } \\
\text { Toma aqui uns } 50 \text { reais..." }\end{array}$ \\
\hline & \\
\hline
\end{tabular}

Quadro 2: Sequência de Emojis como produções discursivas imagéticas

Na figura 8, uma das alunas, como forma de justificar seu equívoco interpretativo, insere um arquivo de áudio afirmando: "Eu também pensava que era esse, Rose". Ou seja, a leitura que foi realizada da imagem, desconsiderou certos elementos icônicos e sua sequência, ficando apenas na superfície do conhecimento prévio partilhado pelas alunas.

Como se pode perceber, mesmo diante de informações já conhecidas, é necessário um Letramento Digital que direcione o leitor/autor para as possibilidades concretas de produção discursiva. Ou seja, o que quero dizer, de que forma posso dizer e quais minhas 
condições de produção. No caso das figuras presentes na produção discursiva em análise, 0 processo de interpretação e compreensão deve ser guiado pelo desenvolvimento de habilidades e competências comunicativas que se ancorem no Letramento em SMS, especificamente no que diz respeito à prática comunicativa em ambiente de redes sociais que façam uso de mensagens instantâneas, como o WhatsApp; e o Letramento multimídia, que abarca não apenas a convergência de vários formatos de arquivo como: vídeo, áudio, imagem, mas também, a maneira como a imagem se apresenta enquanto signo ideológico constituído por outro signos.

A partir de nossas leituras e das análises aqui realizadas, concordamos em primeira instância com duas assertivas de Coscarelli (2016): primeiro, que atividades de leitura e produção de discursos têm como base a esfera digital "levam os estudantes a compartilhar impressões, trocar informações, aprender com os pares e construir significados partilhados a partir dos textos que leem"; segundo, que a leitura em ambiente digital também segue certos propósitos e critérios específicos, mas que, além disso, “significa usar a informação de forma criativa e inovadora para desenvolver novas ideias e resolver problemas complexos".

\section{Considerações Finais}

Percebeu-se ao longo desta experiência, apesar de estarmos imersos num habitus tecnológico digital e de fazermos uso de artefatos digitais em nossas ações cotidianas, os estudos e a prática do Letramento digital, ou melhor, do Macroletramento Digital, uma vez que este abarca uma variedade de letramentos, que convergem para o desenvolvimento competente do sujeito leitor/autor nos espaços digitais, ainda é muito incipiente dentro da sala de aula, apesar dos alunos fazerem uso da linguagem da internet diariamente.

No que tange ao discurso multimodal/multissemiótico, um dos seus maiores propagadores foi Kress e Van Leween (1996), que inauguraram uma proposta de análise do discurso imagético, por meio de categorias elencadas na Gramática do Design Visual, esta última partindo do princípio da Gramática Sistêmico-Funcional de Halliday (1994, 2004). No entanto, embora o universo tecnológico digital seja predominantemente imagético, 
multimodal e multissemiótico, estar letrado visualmente é apenas uma das habilidades inseridas no Letramento multimídia.

Como foi ressaltado nas análises, as imagens representadas pelos emojis só fazem sentido se utilizadas dentro de determinadasequência enunciativa, como foi o caso da proposta inicial de atividade apresentada aos alunos. Isso porque nem todos os emojis funcionam enunciativamente sozinhos como portadores de sentido, alguns precisam de um contexto-base que lhes imprima significado.

Nos discursos analisados, vimos que esses ícones funcionaram como elemento de progressão na construção de sentidos. A sequência de emojiss, a exemplo da organização sintática, apontava para a concretude de um enunciado passível de interpretação, isso porque a combinação dos elementos era responsável pela produção de efeitos de sentidos, os quais contavam com o conhecimento prévio do sujeito para sua possível compreensão.

Por isso, defendemos a possibilidade de uso de elementos da semiosfera digital, em nosso caso os emojis, na construção de atividades práticas em sala de aula, com o intuito de desenvolver nos estudantes habilidades de produção, recepção e socialização de discursos multimodais/multissemióticos, a partir de signos que fazem parte de suas ações discursivas triviais. $E$, nesse sentido, inserir o estudante no universo tecnológico por meio de uma prática que leve em conta os vários letramentos que circulam na esfera digital é um pressuposto imprescindível para a formação de um sujeito dialógico, interativo e participativo do contexto que o circunda.

\section{Referências}

BOURDIEU, P. A economia das trocas simbólicas. 5 a ed. São Paulo: Perspectiva, 2004.

COSCARELLI, C. V. (Org.). Tecnologias para aprender. São Paulo: Parábola Editorial, 2016.

DUDENEY, G; HOCKLY, N.; PEGRUM, M. Letramentos digitais. $1^{\text {a }}$ ed. Trad. Marcos Marcionilo. São Paulo: Parábola Editorial, 2016.

HALLYDAY, M. A. K. An introduction of Functional Grammar. London: Edward Arnold, 1994. ; MATHIESSEN, C.M.I.M. An introduction of Functional Grammar. London: Edward Arnold, 2004. 
KRESS, G; T. VAN LEEUWEN. Reading Images. thegrammarof visualdesign. London \& New York: Routledge, 1996.

RIBEIRO, A. E. Textos multimodais - leitura e produção. $1^{\mathrm{a} e d . ~ S a ̃ o ~ P a u l o: ~ P a r a ́ b o l a ~ E d i t o r i a l, ~}$ 2016.

SILVA. A. P. P. de F. Bakhtin. In.: OLIVEIRA, L. A. (org.) Estudos do discurso - perspectivas teóricas. São Paulo: Parábola editorial, 2013, pp.45 - 69.

Data de submissão: 18/09/2018. Data de aprovação: 04/11/2018 